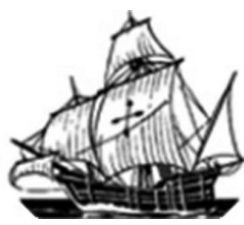

Nau Literária: crítica e teoria de literaturas • seer.ufrgs.br/NauLiteraria

ISSN 1981-4526・PPG-LET-UFRGS • Porto Alegre • vol. 09, n. $01 \bullet$ jan/jun 2013

Dossiê: Voz e Interculturalidade

\title{
DOS VOLTEIOS DO VERBO À GRAFIA DO CORPO: \\ O SAMBA DE RODA NO UNIVERSO DAS LETRAS
}

\section{FROM VERBAL SPINNING TO BODY SCRIPTING: $S A M B A D E R O D A$ IN THE LITERARY UNIVERSE}

\author{
Ilmara Valois Bacelar Figueiredo Coutinho ${ }^{1}$ (UNEB/PUCRS) \\ ilmaravalois@hotmail.com
}

\section{Resumo}

Compreender a importância dos textos poéticos orais ou das grafias do corpo, na área de letras, pressupõe abarcar construções poéticas integrantes da arte performatizada, universo multissensorial e multidimensional, irredutível aos preconceitos ocidentais grafocêntricos ou ao limitado panteão dos gêneros eruditos. Nessa trilha, seguem as reflexões empreendidas no presente estudo, destinado a problematizar o lugar do samba de roda no universo dos estudos literários. Não no sentido de reivindicar sua inserção em qualquer cânone beletrista, mas de colocar questões acerca da existência de manifestações artísticas desterritorializadas em relação à compartimentalização racional moderna dos saberes. Trata-se de um estudo bibliográfico voltado a problematizar o papel das (não)palavras pertencentes aos conhecimentos arquivados na voz, no corpo, no movimento, reconhecendo que é enquanto obra de arte performática de encruzilhada (MARTINS, 2006) que o samba de roda efetiva sua apresentação na roda das "letras". Performance é aqui entendida como o momento no qual se dá, de fato, a interação entre produtores e receptores, numa atualização que acontece conforme cada configuração situacional conhecimento grafado na memória do gesto -, encontrando em Zumthor (2005; 2000; 1997; 1993) e Martins (2006) as bases teóricas que fundamentam as principais reflexões.

Palavras-chave: Samba de roda. Literatura. Performance.

\begin{abstract}
To understand the importance of poetic oral texts or body scripting in the literary area, we need to approach poetic constructions from the area of performance art. This multisensory, multidimensional universe lies beyond the limitations of Western written-focused knowledge and the pantheon of scholastic genres. The following reflections discuss the place of samba de roda in the universe of literary studies. We undertake this task not with the pretension to try to include
\end{abstract}

${ }^{1}$ Professora da Universidade do Estado da Bahia (UNEB). Doutoranda em Letras, área de concentração: Teoria Literária (UNEB/PUCRS). 
samba de roda as part of a literary canon, but to raise questions in relation to the existence of deterritorialized art-forms that have been excluded by the rational compartmentalization of modern knowledge. It is a bibliographic study that questions the role of the (non)words transmitted by the voice, the body and its movement in samba de roda performance art. We recognize the place of samba de roda as borderline performance art (Martins, 2006) in the literary universe. Performance art is understood as the moment in which producers and receivers interact in an artistic presentation that unfolds in situational configurations, as meaning scripted in the memory of gestures. The theoretical foundations that underlie the main ideas of this study are to be found in Zumthor (1993, 1997, 2000, 2005) and Martins (2006).

Key Words: Samba de roda. Literature. Performance. INTRODUÇÃO

A história da literatura são muitas histórias. Enquanto insistimos na edificação de uma grande narrativa capaz de sintetizar produções diversas à luz de uma essência metafísica, a multiplicidade de materializações literário-culturais esgarça campos simbólicos colocando novas questões aos arquivos existentes, fazendo eclodir outros arquivos com questões diferenciadas e exigindo um deslocamento do olhar acerca do que vem a ser as poéticas da voz, a arte literária. Não é difícil perceber, ainda hoje, problematizações acerca das centralizações/marginalizações edificadas na "ordem do discurso" (FOUCAULT, 2002) eleito como literário, o que tem ocorrido a partir da emergência de pontos de tensão voltados a rasurar conceituações dicotômicas, lineares, totalizantes, talvez, com maior intensidade no universo contemporâneo, voltado a celebrar a fragmentação, a velocidade, a mobilidade.

Derivado da palavra littera, letra, o vocábulo literatura esteve historicamente implicado com a totalidade de saberes referentes às artes da escrita, criando lugares enunciativos legitimadores de práticas segregacionistas voltadas a manter realizações literárias da voz, do corpo, à margem de qualquer universo canônico. Por muito tempo, a primazia "naturalizada" do escrito acarretou um direcionamento dos estudos acadêmicos para suas próprias textualidades, de forma que as produções realizadas fora de seus domínios não eram dignas de estudo. O privilégio da linguagem escrita, na longa tradição ocidental dentro das academias, tanto ocasionou o apagamento das poéticas orais, como reduziu o seu estudo ao escrito. De fato, ainda há uma tendência para, ao se analisar textos performatizados, ressaltar a textualidade escrita, mesmo que sua presença seja mínima.

Compreender a importância dos textos poéticos da voz ou das grafias do corpo, na área de 
letras, pressupõe abarcar construções poéticas integrantes da arte performatizada, universo multissensorial e multidimensional irredutível aos preconceitos ocidentais grafocêntricos ou ao limitado panteão dos gêneros eruditos. Nessa trilha, seguem as reflexões empreendidas no presente texto, estando voltadas a problematizar o lugar do samba de roda no universo dos estudos literários. Não no sentido de reivindicar sua inserção em qualquer cânone beletrista, mas de colocar questões acerca da existência de manifestações artísticas desterritorializadas em relação à compartimentalização racional moderna dos saberes e que somente se encaixam em uma disciplina, ou área do conhecimento, capaz de orientar estudos pautados por ramificações interdisciplinares, como podemos considerar a literatura, entendida como cultura. Trata-se de uma discussão apoiada em fontes bibliográficas, de forma que não serão realizadas análises acerca da performance enquanto realização empírica. Entretanto, as discussões mais específicas sobre o samba de roda farão referência à região do recôncavo, estando apoiadas no Dossiê IPHAN: Samba de roda do Recôncavo Baiano (SAMBA, 2006).

\section{POÉTICAS ORAIS E LITERATURA}

Fortemente ligada ao universo do nacionalismo oitocentista, a literatura, enquanto disciplina ou arte da palavra, criou zonas de atrito em relação à oralidade. Ainda hoje, é possível observar um certo desconforto em relação às pesquisas voltadas às poéticas da voz no âmbito das letras, universo voltado a perpetuar a escrita como "veículo de modernidade, racionalidade e como valor do intelecto" (FINNEGAN, 2008, p. 20), enquanto a oralidade é acusada de abrigar discursos supersticiosos, primitivos, grosseiros, espontâneos, emocionais. Há um ranço beletrista na forma como os estudos de "literatura" oral são entendidos, enquanto os rótulos depreciativos continuam a ser utilizados: "paraliteratura", "subliteratura", "literatura de analfabetos", entre outros. Nesse gesto etnocêntrico de desvalorizar o universo cultural que fundamenta a produção, divulgação e fruição dos eventos da voz, encontra-se a tentativa de fazer menor "a voz da praça pública" (BAKHTIN, 1992) e seus anseios, porquanto representam modelos culturais diferenciados e estranhos às restrições elitistas.

Conforme Alcoforado (2007), a parceria/cisão oral/escrito teve início na Grécia, século V a. C., com a transição operada (da oralidade para a escrita) nos poemas épicos de Homero, 
considerados, pela historiografia literária ocidental, como o grande marco da "alta" literatura. Desde então, tal parceria está fundada por jogos discursivos voltados a marcar lugares de poder, inclusive ocasionando o apagamento das bases orais de tal produção escrita, bem como a desvalorização das tradições orais anteriores a esse grande marco, e que continuaram a existir, por exemplo, na força da voz e no aspecto teatralizado dos textos recitados e cantados na literatura medieval ou mesmo nas múltiplas manifestações artísticas orais que cruzaram os séculos margeando cânones e hoje caracterizam a inegável explosão poético-performática das periferias.

O desenvolvimento progressivo da cultura escrita, através dos tempos, segue legitimando suas próprias produções. Tal situação ganha contornos bem nítidos durante "a revolução cultural da Renascença" (SHOLES; KELLOGG, 1977, p. 12), quando fica firmada uma das dicotomias mais excludentes do oral: "popular" versus "erudito". As artes da voz, e seus elementos performanciais, em contraponto ao requintado, complexo e erudito mundo da escrita, sofreram apagamentos geradores de caracterizações depreciativas. Inegavelmente, as denominações literatura oral ${ }^{2}$, e popular, na forma como foram concebidas, estiveram sempre ligadas à ideia de gêneros menores dentro do sacralizado universo literário.

Esta perspectiva foi fortemente questionada em pesquisas desenvolvidas acerca da "poesia oral", principalmente a partir das décadas de 70/80, dentre as quais figuram basilares aquelas realizadas por Paul Zumthor (1993), quando as especificidades da voz são evidenciadas de maneira a firmar um campo de atuação próprio, capaz de abarcar experiências literárias cujo veículo principal de transmissão fosse o corpo e não a página impressa. Somados às vozes questionadoras do discurso literário convencional, em sua inadequação para compreender textos fundadores, a exemplo dos de Homero (em seus constituintes orais), os estudos de Zumthor (1993) desencadearam uma série de reflexões críticas que levaram o termo literatura, em suas conceituações e desdobramentos, a serem colocados sob rasura.

As consequências epistemológicas dos chamados estudos medievalistas incidem diretamente sobre alguns cismas grafocêntricos da história literária, culminando estudos direcionadas a destacar as particularidades das poéticas da oralidade como estratégias de

\footnotetext{
${ }^{2}$ Em 1881, Paul Sébillot, em Littérature Oral de la Haute-Bretagne, explica o termo literatura oral, cujo primeiro registro é a ele atribuído, como produção literária de pessoas que não lêem, mas que se vinculam à literatura, desencadeando conceitos e preconceitos.
} 
constituição "estética" e não como primitivismo ou falta de cultura. Sendo a "literatura" preponderantemente oral em suas origens, é preciso reconhecer que a mesma emana do movimento, da voz, do corpo, da performance. Tudo o que as sociedades ocidentais modernas se esforçaram para disciplinar (FOUCAULT, 2004) e controlar.

Uma tal descentralização do cânone não se faz sem controvérsias e disputas. Se, inicialmente, a questão da literatura, em suas realizações orais e escritas, foi encaminhada como uma diferenciação de gênero, literatura oral/popular e literatura escrita/erudita, a partir de tais estudos, percebeu-se ser essa construção insuficiente para dar conta dos diversos campos de atuação desses dois grandes vetores da linguagem humana e suas leituras. Nesse movimento de firmar um campo de estudos próprio para a voz, sem submetê-lo ao grafocentrismo, etimologicamente e historicamente, característico da literatura, Paul Zumthor (2007, p. 12) argumenta:

[...] o que tenho de eliminar é o preconceito literário. A noção de 'literatura' é historicamente demarcada, de pertinência limitada no espaço e no tempo: ela se refere à civilização européia, entre os séculos XVII ou XVIII e hoje. Eu a distingo claramente da idéia de poesia, que é para mim a de uma arte da linguagem humana, independente de seus modos de concretização e fundamentada nas estruturas antropológicas mais profundas (grifos do autor).

Foi dessa perspectiva que me coloquei o problema da poesia vocal (insisto no adjetivo) e afastei os pressupostos ligados à expressão, infelizmente frequente, 'literatura oral'.

Fica patente a busca por uma compreensão abrangente acerca das construções poéticas orais, não mais possíveis de serem analisadas sob a tutela da escrita. Enquanto evento artístico complexo, o texto oral passa a ser compreendido como performance (condição incontornável de existência), requerendo estudos capazes de problematizar a sua compreensão, a partir de elementos basilares como: o lugar, o momento, a expressões do corpo, o ritmo da melodia e da voz que canta ou declama, a corrente de energia que se estabelece entre poeta e público, as reações, intervenções realizadas pelo público, a ambiência cultural. Nessa trilha, critérios destacados tradicionalmente para a literatura oral, como antiguidade, persistência e anonimato (CASCUDO, 1986), são questionados, inclusive, porque o poeta (ou grupo) da oralidade passa a figurar importante para a compreensão da obra. 
Ruth Finnegan (2008, p. 22-23) ressalta alguns fenômenos atuais decisivos para a emergência de estudos voltados aos gêneros performáticos, a saber: o movimento transdisciplinar voltado a compreender processos, diálogos, ações e contextos mais que produtos; a emergência de desafios postos à estreiteza dos cânones da arte erudita, com a emergência da arte de povos colonizados/marginalizados e de gêneros híbridos transnacionais; o desenfreado desenvolvimento das novas tecnologias da comunicação e da informação, em sua mutabilidade constante.

É preciso destacar que os estudos pós-coloniais/pós-modernos ocasionaram abrangente renovação teórica no campo da literatura, com o despontar de novos questionamentos acerca do caráter político-ideológico das certezas metafísicas literárias. Sob a batuta dos estudos da cultura, quando não dos estudos culturais, formas literárias não-escritas passaram a povoar universos de pesquisas outrora exclusivos das letras. Ao abalo já sofrido por dois dos pilares mais caros à historiografia literária tradicional, a saber, as ideias de nação (entendida como comunidade imaginada) e idioma (construto político hegemônico), acrescente-se a noção de "literariedade", problematizada no sentido de incluir o popular, o oral, o discurso de grupos étnicos marginalizados e seus outros padrões estéticos. Como lembra Pascale Casanova (2002, p. 63), “A ideia pura de uma literatura pura dominar o mundo literário favorece a dissolução de todos os vestígios da violência invisível que nele reina [...]", realidade não mais possível de ratificar, pois os processos violentos de colonização, em várias frentes, são, cada vez mais, questionados.

No bojo dos estudos sobre performance, a literatura vem assumindo seu lugar de encruzilhada, constelando eventos artísticos híbridos. Conforme Martins (2006), a encruzilhada é uma instância simbólica geratriz de sentidos plurais. A sua formação radical indica, simultaneamente, centralização e descentralização, fazendo-se espaço potencial de interconexões e desvios constantes. A encruzilhada, como é entendida por Martins (2006, p. 65), e como procuro destacar no presente texto, é o lugar da discursividade, da intertextualidade, da transculturalidade:

[...] na concepção filosófica nagô/yorubá, assim como na cosmovisão de mundo das culturas banto, a encruzilhada é o lugar das intermediações entre sistemas e instâncias de conhecimentos diversos, sendo frequentemente traduzida por um cosmograma que aponta para o movimento circular do cosmos e do espírito humano que gravitam na circunferência de suas linhas de intersecção. (MARTINS, 2006, p. 65) 
Nessa perspectiva, a encruzilhada apresenta-se como categoria produtiva para uma compreensão acerca dos estudos literários, em contextos de pós-modernidade, pós-colonialidade e, por que não dizer, pós-"literariedade", em sua emergente necessidade de abdicar de uma postura etnocêntrica, grafocêntrica e outros "centrismos". Assumir as "linhas de intersecção", a transversalidade que lhe é solicitada (mesmo não fazendo parte da etimologia ou dos contornos nacionalizantes que lhes foram atribuídos), representa assumir a diversidade de manifestações, que, desde tempos remotos até hoje, fazem parte de sua artesania Em tempos de globalização, em

que a conveniência da cultura é uma realidade, figurando como "recurso" (YÚDICE, 2006), entender processos de produção, circulação e consumo de literatura e cultura, torna-se fundamental, inclusive porque o destaque dispensado às manifestações populares e orais, muitas vezes, continuam restritas a territórios vigiados e subfinanciados, como diria Hall (2006).

Nessa artesania múltipla, podemos situar o samba de roda, entendido como manifestação musical, coreográfica e poética irredutível ao escrito ou ao individualismo solitário característico de muitas produções ocidentais, posto mobilizar sistemas comunicacionais e semióticos variados, sendo ele mesmo encruzilhada.

\section{O SAMBA NA RODA DO RECÔNCAVO BAIANO}

Historicamente, o universo territorial e simbólico do Brasil foi-se constituindo de maneira desigual, posto estar comprometido com pressupostos limitadores, no que tange às manifestações culturais ditas populares. As expressões tradicionais afro-brasileiras, desenvolvidas, em sua maioria, no âmbito das artesanias performáticas, passaram por um progressivo processo de apagamento e desqualificação gerador de invisibilidade, o que fez com que diferenças (racializadas) fossem tomadas como desigualdades, em várias frentes, inclusive, como critério valorativo para as produções artísticas classificadas pejorativamente como folclóricas.

Nesse contexto, o samba foi se formando e transformando no sentido de produzir lugares potencializadores de resistência e de preservação dos traços culturais de matriz africana, representando importante expressão identitária afro-brasileira. Como nos lembra Sodré:

Nos quilombos, nos engenhos, nas plantações, nas cidades, havia samba onde estava o negro, como uma inequívoca demonstração de resistência 
ao imperativo social (escravagista) de redução do corpo do negro a uma máquina produtiva e como afirmação de uma continuidade do universo cultural africano. (SODRÉ, 2007, p. 12)

Proveniente de trânsitos diaspóricos realizados a partir da cultura negra em sua dispersão no Brasil, o samba preservou traços culturais africanos, sem deixar de dialogar com as culturas com as quais interagiu, tomando formas diferenciadas no vasto território geográfico e simbólico do país. Entretanto, uma característica permanece comum a todas as formas de realização: a vocação celebratória por agregar sistemas de comunicação diferenciados, fazendo cruzar gestos, cores, sons, ritmos, palavras, crenças, mitos, enfim, conjugar cosmogonias dificilmente cabíveis em estudos voltados a uma racionalidade positivista, afeita a bipolarizar o conhecimento.

O samba de roda está presente na cultura de várias regiões do país, mas o recôncavo baiano é seu tempo/lugar de existência consolidada, seu universo referencial e semântico mais notável. Berço da cultura tradicional africana durante a colonização do estado, a região vivenciou, como nenhum outro lugar, a constituição integradora de universos simbólicoconceituais característicos dessa parte da África escravizada no Brasil e suas (re)elaborações diaspóricas. Sendo, desde as primeiras referências, citado como parte integrante das atividades econômicas, religiosas e lúdicas da região, atravessou os séculos (entre)tecendo o universo cultural das comunidades locais.

Ainda hoje, é evento indispensável, tanto em ocasiões festivas do cotidiano, quanto em momentos solenes que caracterizam a região. Dessa forma, é apresentado durante as festas do catolicismo popular (associadas a tradições religiosas afro-brasileiras), nas festas dos santos Cosme e Damião, nos culto aos caboclos, depois das festas de candomblés de rito nagô ou angola, nas festas de Nossa Senhora da Boa Morte ${ }^{3}$, entre tantos outros momentos de celebração (SAMBA, 2006).

Chama-se samba de roda por conta da forma, preferencialmente, mas não única, circular de organização dos participantes que, em geral, distribuem-se em uma roda onde tocam, cantam, batem palmas e dançam (em muitos casos uma pessoa dança no interior da roda, por vez, enquanto os outros acompanham batendo palmas e cantando). Muitos grupos de samba formam o

\footnotetext{
${ }^{3}$ A festa da Irmandade de Nossa Senhora da Boa Morte ocorre, desde 1820 até os dias atuais, na cidade de Cachoeira, localizada no Recôncavo Baiano, a 116 quilômetros de Salvador.
} 
universo cultural do recôncavo, fazendo espetáculos compostos por ritmos, instrumentos e passos característicos, mais ou menos comuns (mas não únicos), quando materializam performances tecidas a partir de repertório musical e coreográfico de complexidade e beleza singulares. Declarado Patrimônio Oral e Imaterial da Humanidade, desde 25 de novembro de 2005, pela UNESCO, o samba de roda guarda, em seu caráter integrador de diversas artes, valor cultural incontestável, como está ressaltado no "Dossiê IPHAN" (SAMBA, p. 70-71, 2006):

A magnitude do valor do samba de roda como bem cultural reside em seu conjunto. Ele é dança, é música, é poesia, é inclusive teatro, posto que apresenta cenários, indumentária e papéis a serem desempenhados. E é não menos importante - participação: a alegria máxima do samba reside em fazer parte dele, em sambar.

Nesse sentido, compõe-se de uma materialidade somente passível de reflexão levando-se em conta o conjunto performancial de sua existência concreta, um dos motivos pelos quais sua presença, em pesquisas realizadas na seleta roda dos cursos de letras, somente acontece no bojo de abordagens adicionais àquelas voltadas a separar o texto da música ou a descaracterizar as obras de arte ditas populares. Nas trilhas da diferenciação feita por Paul Zumthor (1993) entre texto e obra, diríamos que mais que texto, o samba de roda é obra, porquanto inclui a totalidade dos atos presentes na performance, sendo o "sentido" do texto escrito apenas uma parte, que não pode ser dita a mais importante, da experiência fruidora moldada a partir das circunstâncias de sua constituição formal, de sua ritualidade, enquanto espetáculo.

Qualquer estudo acerca de sua constituição, caso busque ater-se a apenas uma das linguagens mobilizadas em sua artesania, corre o risco de mutilar a obra, pois sua existência não se encontra somente na partitura, nos passos da dança ou no texto escrito, tão pouco, em nenhuma essência metafísica a ser apreendida em técnicas estruturalistas de estudo, mas na materialização de todos os elementos disponíveis e afeitos a se aglutinarem, num indivisível ato performatizado inserido socioculturalmente.

\section{O SAMBA DE RODA COMO PERFORMANCE}

O samba de roda é, incontornavelmente, performance. Em qualquer palco, meio ou suporte, em que seja vinculado, requer do expectador um olhar/corpo holisticamente direcionado 
para o caráter plurissêmico de sua artesania. O processo global e agregador dos fragmentos constitutivos de cada apresentação exorta uma co-presença, em ato único de participação, em cuja totalidade engaja os corpos dos participantes (ZUMTHOR, 1993, p. 244).

Em tal artesania, não é raro observar apresentações de força poético-performática inclusiva, capaz de envolver a todos os participantes na mesma fruição vital, quando o palco, ainda que exista enquanto materialidade física, parece dissolver-se, tal o nível de integração protagonizado entre os componentes dos grupos de samba e o público. Em tais eventos, a performance, entendida como momento no qual se dá, de fato, a interação entre produtores e receptores (ZUNTHOR, 2007), torna-se ritual destinado a celebrar memórias e experiências de vida das comunidades.

Para o entendimento do samba de roda como performance, além dos elementos performanciais mais voltados ao aqui-agora característico de cada evento (intérprete, auditório, as circunstâncias, as relações intersubjetivas, entre outros já citados), duas questões parecem-me relevantes, nesta reflexão ainda inicial. A primeira, refere-se ao fato de o evento poéticoperformático do samba de roda ser entendido como comunicação humana, e cósmica, mediada por recursos multimodais integrantes da cultura de matriz africana no Brasil. Não é sem motivos que o samba de roda seja presença marcante em momentos de confraternização e comunhão cultural no recôncavo baiano, inclusive em festas religiosas, em cujas teias a música e a dança são ritos de fé. Aí reside a importância de se levar em conta o sistema de trocas simbólicas dos grupos locais, inclusive no que tange às formas como estão sendo concretizadas as atualizações artísticas.

A performance do samba de roda mais que espetáculo a ser fruído, mais que conteúdo e forma, técnica e estética, brincadeira e festa, faz-se troca sociocultural destinada a comunicar conhecimentos, sentimentos, memórias, marcando presença de um lugar cultural, muitas vezes, destinado ao apagamento nas cadeias discursivas da história. Considerando que nenhum dos componentes do ato performativo realiza-se de forma autônoma, sua materialização deve ser considerada, inclusive, no sentido de entrecruzar mundos, como nos lembra Sodré, ao tratar dos sentidos da música para a cultura tradicional africana e sua possibilidade de significância voltada a "[...] acionar o processo de interação entre os homens e entre o mundo visível (o aiê, em nagô) e o invisível (o orum)" (SODRÉ, 2007, p. 21). 
Assim, uma compreensão abrangente acerca do valor atribuído ao som, ao ritmo, ao corpo em culturas de matriz africana, pede abordagem diferenciada. Ainda conforme Sodré (2007, p. 20), no sistema gêge-nagô ou iorubá, “o som é condutor de axé, ou seja, o poder ou força de realização, que possibilita o dinamismo da existência”. Nesse entendimento, o som se faz na presença do corpo, em contato com outro corpo, a fim de que o axé possa ser acionado. Inegavelmente, o engajamento do corpo em qualquer ato de performance é essencial.

No caso do samba de roda, obra partícipe de eventos sagrados e profanos, faz-se pertinente considerar tratar-se de corpos que precisaram grafar conhecimentos na própria carne, reverberando ritmos, movimentos e monumentos inacessíveis ao controle do colonizador. Corpos ritualmente engajados no momento único e jamais repetível de espetáculos a serem fruídos com prazer, muitas vezes, sagrado. Corpos destinados à (re)elaboração estética de um acontecimentoarte, voltado a materializar volteios desencadeadores de interação entre espaços, tempos e mundos. Corpos projetados como saberes indisciplinados (FOUCAULT, 2004), fazendo-se evento, espetáculo, obra, arte.

A segunda questão, entrelaçada à anterior, mas não restrita a ela, trata de memórias/esquecimentos e de uma contextualização que acompanha o aqui-agora do evento performático. Nas relações desenvolvidas entre colonizador e colonizado (tanto em momentos de colonização como de descolonização), muitos apagamentos foram sendo processados, por meio de violências físicas e simbólicas afeitas a firmar verdades que se queriam inquestionáveis. Entretanto, toda uma gama de conhecimentos ramificados à margem dos holofotes elitistas permaneceu no corpo e na voz negros, através da performance, construindo uma forma de inscrição de saberes inalcançáveis aos poderes escravistas, em suas múltiplas formas de materialização no correr da história.

Como ressalta Finnegan (2007), não podemos deixar de considerar, nos trânsitos existentes entre presente/passado, uma presença/ausência constante de outras performances, travando diálogos com cada aqui-agora e fazendo circular sentidos moldados a partir das experiências compartilhadas pelos participantes. Sendo explosão vivida no momento da apresentação, o samba de roda não deixa de ser evento destinado a reverberar memórias e esquecimentos ancestrais moldados no correr dos anos, por meio dos desafios vivenciados, das grafias rasuradas historicamente no próprio corpo, das celebrações culturais metaforizadas em 
poesia. Cada performance é singular. E sendo única, tem a propensão por ser muitas. O evento arte do samba, em seu caráter efêmero de performance, mesmo não tendo a obrigatoriedade de fixar "verdades" inquestionáveis, faz materializar lembranças e esquecimentos, constantemente (re)configurados por meio das diversas temporalidades sincronizadas em sua constituição.

Nessa perspectiva, faz-se relevante ressaltar os estudos efetivados por Leda Martins acerca da oralitura, quando estuda os Reinados ou Congados, em Minas Gerais. O sentido do termo oralitura (litura/litera), segundo a autora, filia-se não à tradição linguística, mas "ao que em sua performance indica a presença de um traço cultural estilístico, mnemônico, significante e constitutivo, inscrito na grafia do corpo em movimento e na vocalidade" (MARTINS, 2006, p. 84). A rasura provocada em relação ao vocábulo oratura, usado por pesquisadores em referência à tradição oral africana para marcar a textualidade verbal, efetiva-se no acréscimo da linguagem performática presente na memória do corpo. Assim, a autora destaca que,

Se a oratura nos remete a um corpus verbal, indiretamente evocando a sua transmissão, a oralitura é do âmbito da performance, sua âncora; uma grafia, uma linguagem, seja ela desenhada na letra performática da palavra ou nos volejos do corpo. Numa das línguas banto, da mesma raiz verbal (tanga) derivam os verbos escrever e dançar, o que nos ajuda a pensar que, afinal, é possível que não existam culturas ágrafas, pois segundo também Nora (1996), nem todas as sociedades confiam seus saberes apenas em livros, arquivos, museus e bibliotecas (lieux de mémoire), mas resguardam, nutrem e veiculam seus repertórios em outros ambientes da memória (milieux de mémoire), suas práticas performáticas. (MARTINS, 2006, p. 84)

A memória oral afro-descendente faz-se por meio do corpo em performance, de onde emanam poesia, música e dança, em diálogos continuamente (re)elaborados entre tradição e ruptura. Nesses "volejos", são (re)territorializadas malhas culturais e poéticas que fazem a obra de arte. Por isso mesmo, tratar de contextualização histórica, de esquecimentos e memórias, referentes à performance do samba de roda, não significa buscar estabelecer uma genealogia purista para os eventos afro-brasileiros de arte, mas destacar que os deslocamentos necessárias às novas demandas socioculturais não negam o valor das construções passadas, posto materializarem "enraizamentos dinâmicos" (MAFFESOLI, 2007, p. 116) voltados a dialogar conhecimentos edificados por meio de experiências individuais/coletivas que fazem a cultura, a 
sociedade, a arte. Mais que produto, as poéticas orais são eventos artísticos performáticos em eterno devir. Dessa forma, seguem (re)fazendo-se e (re)inventando-se enquanto se (re)inventam aqueles que fazem sua artesania.

\section{CONSIDERAÇÕES FINAIS}

A beleza dos arquivos poéticos orais encontra-se em sua possibilidade de (re)criação contínua, em sua artesania afeita à criação de múltiplas "verdades"; acontecimento que o espírito racionalista moderno jamais foi capaz de compreender ou aceitar, tão imbuído estava na tarefa de fixar saberes generalistas o suficiente para abarcar realidades múltiplas, díspares, por vezes, inconciliáveis. Curiosamente, depois de séculos de apagamento, chegamos à lição que muitas poéticas orais, em sua mobilidade indisciplinada, sempre pareceram guardar: a relativização das "verdades", o caráter rizomático da construção do conhecimento, a teatralidade inerente às redes discursivas irredutíveis a um único olhar. Mesmo não querendo simplificar exacerbadamente as condições de existência das poéticas orais, não posso deixar de afirmar que os pressupostos líquidos, fragmentários e moventes, hoje eleitos para caracterizar a pós-modernidade (certo que em outra proporção), estiveram na base das trocas culturais e artísticas orais e populares, desde tempos imemoriais, inclusive, em sua propensão por circular a territorialidade terrestre quando não dispúnhamos de "tecnologias" para tal, a não ser o corpo e a voz (como aconteceu com os contos de tradição oral), embora tenhamos insistido em classificá-las a partir de uma ótica reducionista.

Em contraponto à tendência (necessidade) de criarmos arquivos estáticos capazes de petrificar saberes por meio de palavras escritas, os arquivos moventes da voz não deixaram de marcar existência fundada no entre-lugar regional/global das tradições e deslocamentos. Hoje, faz-se mister reconhecer que, mais que antiguidade e anonimato, as poéticas orais são entendidas como experiências culturais em constante processo de construção e cujas características diferenciadas exigem abordagem também diferenciada. Nesse sentido, ressalte-se a necessidade de ultrapassarmos julgamentos valorativos ou comparativos afeitos a colocar as poéticas do corpo e da voz em posição de arte menor, em relação à escrita (o mais difícil?)

Os estudos literários, entendidos como cultura, não mais enjaulados às limitações grafocêntricas, acabam por se colocar na encruzilhada das linguagens, acolhendo gêneros 
híbridos performáticos afeitos a entrecruzar formas e sentidos, o que pressupõe aceitar o desafio de que as respostas não estão prontas e que múltiplas possibilidades continuam a permear conflitos integrantes à construção de campos de conhecimentos destinados a (re)inventarem seus pressupostos ad infinitum. Os desafios postos, aos estudos contemporâneos literários, desenvolvem-se no sentido de problematizar o papel das (não)palavras, nesse todo significativo voltado a mobilizar conhecimentos arquivados no próprio corpo. Enquanto objeto seccionado, o samba de roda pode ser estudado por disciplinas diversas, afeitas a tomá-lo, metonimicamente, a partir de cada campo de interesse. Entretanto, é enquanto obra de arte performática de encruzilhada, fazendo entrecruzar os volteios do verbo às grafias do corpo, que o samba de roda pode apresentar-se pleno na roda das "letras".

\section{REFERÊNCIAS}

ALCOFORADO, Doralice F. Xavier. Oralidade e literatura. In: LEITE, Eudes Fernandes; FERNANDES, Frederico. (Orgs.). Oralidade e Literatura. Londrina: EDUEL, 2007.

BAKHTIN, Mikhail M. Estética da Criação Verbal. São Paulo: Martins Fontes, 1992.

CASANOVA, Pascale. "Literatura, nação e política". In: A República Mundial das Letras. São Paulo: Estação Liberdade, 2002. p. 53-64.

CASCUDO, Luis Câmara. Literatura oral no Brasil. 3. ed. São Paulo: EDUSP, 1986.

FINNEGAN, Ruth. O que vem primeiro: o texto, a música ou a performance? In: MATOS, Cláudia Neiva de; TRAVASSOS, Elizabeth; MEDEIROS, Fernanda Teixeira. Travassos; Palavra cantada: ensaios sobre poesia, música e voz. Rio de Janeiro: 7Letras, 2008.

FOUCAULT, Michel. A ordem do discurso. 8. ed. Trad. Laura Fraga de Almeida Sampaio. São Paulo: Edições Loyola, 2002.

FOUCAULT, Michel. Vigiar e punir, Rio de Janeiro: Editora Vozes, 2004.

MARTINS, Leda Maria. A oralitura da memória. In: FONSECA, Maria Nazereth Soares (Org.) Brasil afro-brasileiro. 2. ed. Belo Horizonte, Autêntica, 2006.

SAMBA de roda do recôncavo baiano. Brasília, DF: Ipham, 2006. 216p.

SCHOLES, Robert e KELLOG, Robert. O legado oral na narrativa escrita: a natureza da narrativa. Recife: Macgraw- Hill do Brasil, 1977. 
SODRÉ, Muniz. Samba, o dono do corpo. 2. ed. Rio de Janeiro: Mauad, 1998. YÚDICE, George. A conveniência da cultura: usos da cultura na era global. Tradução de Marie-Anne Kremer. Belo Horizonte: Editora UFMG, 2004.

ZUMTHOR, Paul. A letra e a voz: A literatura medieval. Tradução Amálio Pinheiro, Jerusa Pires Ferreira. São Paulo: Companhia das letras, 1993.

ZUMTHOR, Paul. Performance, recepção, leitura. Tradução Jerusa Pires Ferreira e Suely Fenerich. São Paulo: Cosac Naify, 2007. 